\title{
Canal of Nuck Hernia in a Female Infant Containing Uterus, Bilateral Adnexa and Bowel
}

\author{
Betül Emine Derinkuyu ${ }^{1}$, Mohammad Reza Affrancheh ${ }^{1}$, Didem Sönmez ${ }^{1}$, Meltem Bingöl Koloğlu², Suat Fitoz ${ }^{1}$
}

${ }^{1}$ Department of Radiology, Ankara University School of Medicine, Ankara, Turkey

${ }^{2}$ Department of Pediatric Surgery, Ankara University School of Medicine, Ankara, Turkey

Background: The canal of Nuck is a fold of peritoneum that invaginates into the inguinal canal and closes at or just before birth. If the canal of Nuck remains open in female infants, herniation of the uterus, adnexa and/or bowel loops may arise through the inguinal canal into the labia majora.

Case Report: The present case is a 12-week-old female infant with complaints of left groin swelling and discomfort. Ultrasonographic examination revealed a left inguinal hernia containing both adnexa (ovaries and fallopian tubes), uterus and small bowel loops with fluid.

Conclusion: A hernia containing ovary and uterus should be considered as a possible cause in a female infant with a groin mass. Ultrasonography of the inguinal mass lesions should be performed routinely in a female infant for accurate diagnosis.

Keywords: Hernia, infant, canal of Nuck, ovary, uterus
Inguinal hernias occur commonly in infancy and early childhood. The overall incidence of inguinal hernias in childhood has been reported to range between $0.8 \%$ and $4.4 \%$ which is highest in the first year of life, specifically in premature infants $(1,2)$. The incidence of this condition is up to six times higher in boys than in girls. However, about $15-20 \%$ of hernias in female infants contain ovary (3). Particularly, indirect inguinal hernias containing entire uterus, adnexa (fallopian tubes and ovaries) and bowel loops are exceedingly rare. In this case report we describe a very rare case of a premature female infant who had a left inguinal hernia, containing bilateral ovaries, fallopian tubes, uterus and small bowel loops.

\section{CASE PRESENTATION}

A 12-week-old female infant presented with a tender left groin swelling and discomfort. On physical examination, there was a partially reducible mass in the left inguinal region without any abdominal distension or tenderness. Although the groin mass was slightly movable, it recurred rapidly after an attempt at reduction. Laboratory examination was unremarkable. Ultrasonographic examination was requested to determine the cause of the mass. The patient was examined with a $7.5 \mathrm{MHz}$ transducer and an Apolio scanner (Toshiba Medical Systems Co. Ltd.; Tokyo, Japan). The sonographic exam revealed a sac, containing two echogenic and round mass with multiple tiny cystic structures likely represent follicles; uterus with visualization of endometrial cavity; and small bowel loops (Figure 1). There was also small amount of fluid around these structures. Posteriorly, a fascial defect measuring $10 \mathrm{~mm}$ in diameter was detected (Figure 2). By transducer compression, all the structures in the hernia sac were reducible except left ovary (Figure 3). Doppler ultrasonography demonstrated the normal blood flow to these structures in the hernia sac without any incarceration. According to the physical and sonographic examination, the diagnosis of irreducible indirect inguinal hernia containing uterus, both adnexa and bowel loops was made.

Surgery was performed emergently. The surgical exploration confirmed the preoperative diagnosis of a left inguinal

Address for Correspondence: Dr. Betül Emine Derinkuyu, Department of Radiology, Ankara University School of Medicine, Ankara, Turkey

Phone: +905053514994 e-mail: betulemineyildiz@gmail.com

Received: 4 May $2015 \quad$ Accepted: 11 February 2016 • DOI: 10.5152/balkanmedj.2016.150643

Available at www.balkanmedicaljournal.org

Derinkuyu BE, Affrancheh MR, Sönmez D, Bingöl-Koloğlu M, Fitoz S. Canal of nuck hernia in a female infant containing uterus, bilateral adnexa and Bowel. Balkan

Med J 2016;33:566-8. 

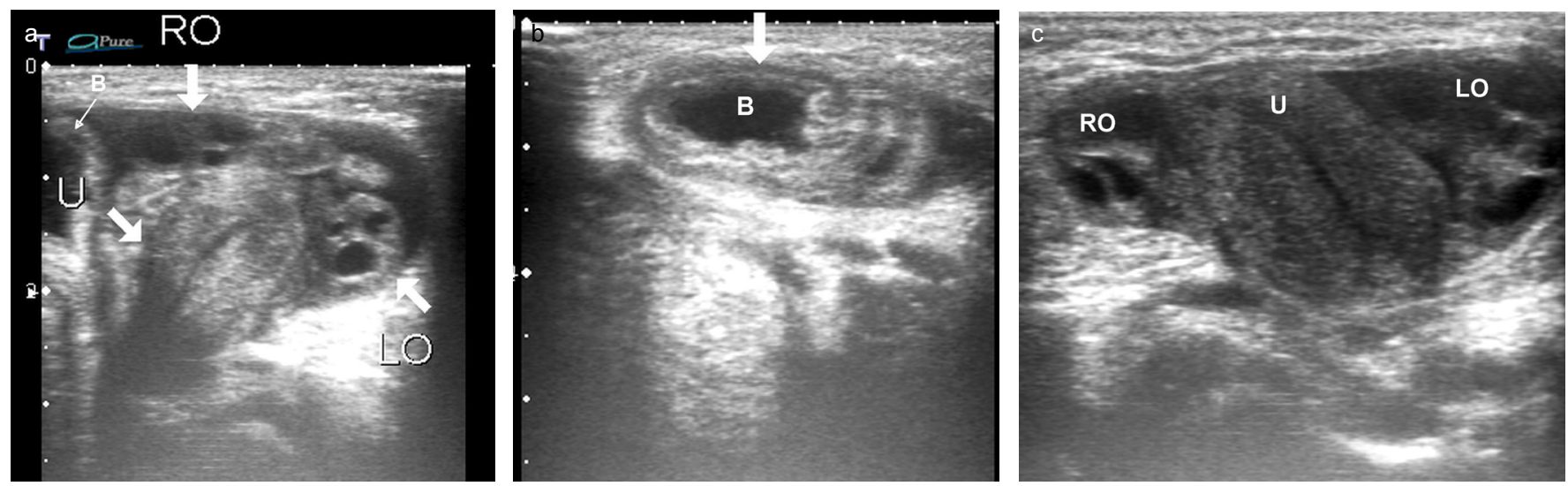

FIG. 1. a-c. Transverse plane sonogram (a) of the left inguinal region medially and labia majora superiorly, shows the hernia sac and its contents (RO: Right ovary; LO: Left ovary; U: Uterus, B: Bowel). Note the anechoic fluid around these structures. Horizontal plane sonogram (b), shows the herniated small bowel loops in the sac medially (white arrow) (B: bowel). Horizontal plane sonogram (c), shows the whole internal genitalia in the sac laterally (RO: right ovary; U: uterus; LO: left ovary).

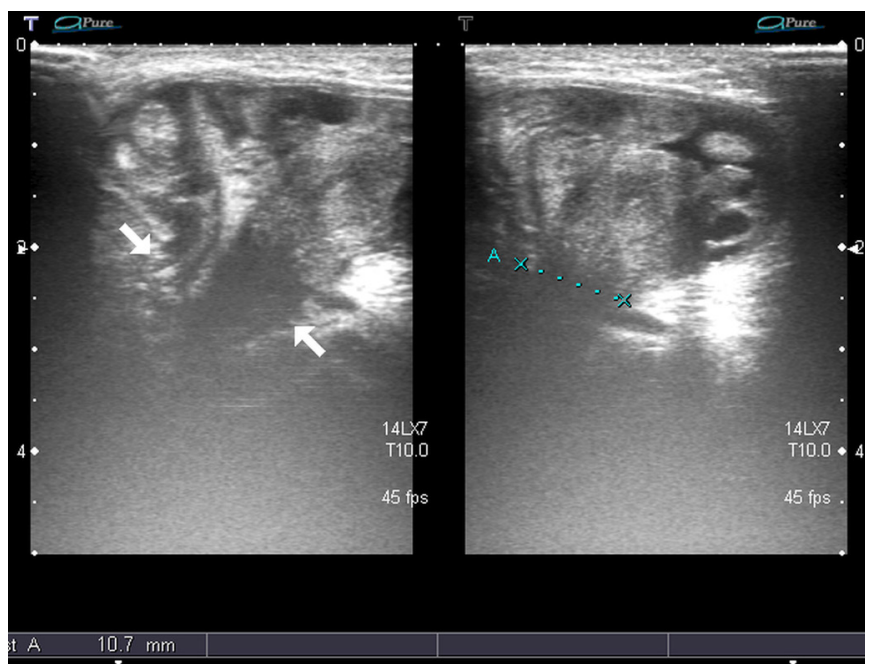

FIG. 2. Transverse plane sonogram; posteromedial to the sac there is a $10-\mathrm{mm}$ fascial defect containing uterus, fallopian tubes and small bowel loops. The whole genital structures and small bowel loops herniated through the subcutaneous adipose tissue.

hernia containing healthy-looking structures, which were easily reduced. Surgical excision of the sac and back-wall repair were performed successfully. Three days later, the patient discharged without any complication. Also, written informed consent form was taken from the parents of the patient before preparation of this manuscript.

\section{DISCUSSION}

Inguinal hernias are the most common form of inferior abdominal wall herniation in children. Embryologically, inguinal canal development necessities anatomic events involving two main anatomic structures, the gubernaculum testis and

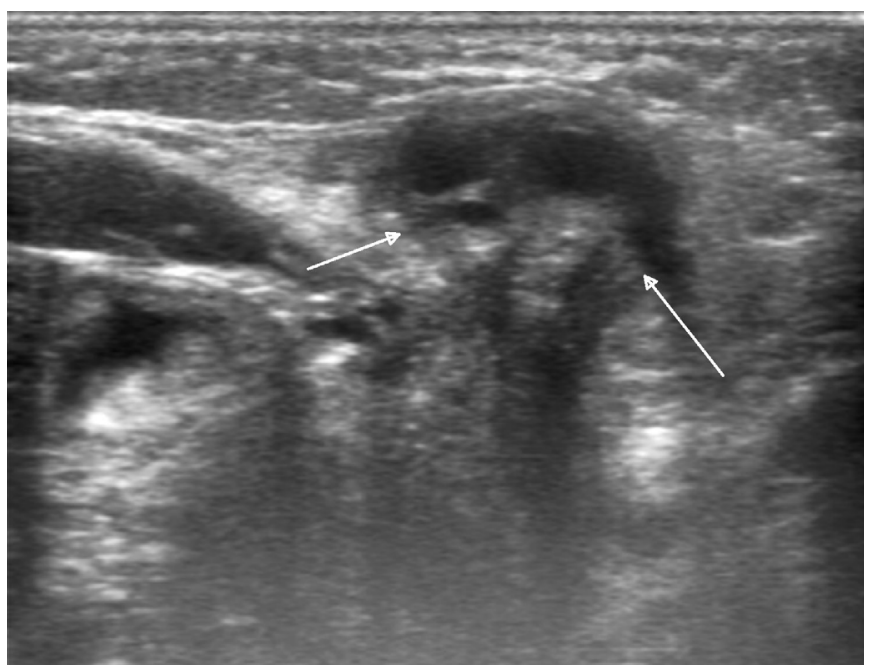

FIG. 3. By the transducer compression, all the structures are reducible with the exception of left ovary (white arrow).

processus vaginalis $(4,5)$. The gubernaculum testis attaches to the skin of the fetal groin inferiorly and to the lower pole of the fetal gonad superiorly. In the male, the gubernaculum assists in descent of the testis through the inguinal canal and into the scrotum. In the female, the gubernaculum attaches to the uterus at its midpoint and prevents ovary to descend into the inguinal canal (4). The processus vaginalis (called the canal of Nuck in the female) is a tubular fold of peritoneum that invaginates into the inguinal canal. The upper part of the canal of Nuck usually closes at or just before birth, and obliteration proceeds gradually in a downward direction (4). If the canal of Nuck remains open, bowel loops and ovary can herniate through the inguinal canal into the labia majora in female infants. 
Inguinal hernias containing ovary are not uncommon in infancy. However, herniation of the uterus is unusual. It has been speculated that there may be an abnormality of the suspensory ligaments of the uterus (3). In the medical literature, only few cases have been reported with inguinal hernias containing uterus and both ovaries $(3,6)$. But, to the best of our knowledge, the patient presented here is the first case of a large canal of Nuck hernia containing whole internal genitalia and small bowel loops. Okada et al. (6), described a hypothesis concerning the potential origin of the inguinal herniation of the entire uterus and adnexa. They asserted that, the broad ligament of the uterus may be induced to track the uterus and contralateral adnexa when the ipsilateral adnexa herniate into the sac.

Ultrasound is the primary modality to examine the groin masses which is an easy and accurate diagnostic procedure. This imaging technique is non-invasive, safe and relatively painless without using any ionizing radiation and does not require injection of a contrast medium. Inguinal hernias, localized fluid collections or enlarged lymph nodes should be considered in the differential diagnosis of the groin masses which could be easily differentiated by ultrasound exam $(5,7)$. For inguinal hernias, the contents of the hernia sac are easily recognized sonographically, because of the specific features of the structures. Ovaries are solid oval structures with a characteristic homogenous echo pattern and multiple tiny cysts representing follicles (7). The uterus is an elongated structure with myometrium and endometrium. To exclude strangulation and incarceration, color and pulsed Doppler evaluation is helpful (4).

In pediatric surgery literature, the risk of incarceration is highly increased in ovary containing hernias in comparison to the bowel containing hernias. It has therefore been suggested that any irreducible hernia containing ovary, even if not tender, should be treated as a surgical emergency (8-10).

To conclude, in a pediatric female patient with a groin mass, ovary containing hernia should be considered as a possible cause, especially in premature infants. The diagnosis of inguinal hernia containing uterus and uterine adnexa was vastly suspected preoperatively by ultrasonogram and confirmed during surgery. Awareness of this possibility may lead to a straight-forward diagnosis on sonography.

\section{Ethics Committee Approval: N/A.}

Informed Consent: Written informed consent was obtained from the parents of the patient.
Peer-review: Externally peer-reviewed.

Author contributions: Concept - B.E.D., M.R.A.; Design M.R.A., D.S.; Supervision - S.F., M.B.K.; Resource - B.E.D., D.S.; Materials - B.E.D., S.F.; Data Collection and/or Processing - B.E.D., D.S., M.B.K.; Analysis and/or Interpretation - B.E.D., M.R.A.; Literature Search - B.E.D., S.F.; Writing - B.E.D., D.S, M.R.A.; Critical Reviews - S.F., M.B.K.

Conflict of Interest: No conflict of interest declared by the authors.

Financial Disclosure: The authors declared that this study has received no financial support.

\section{REFERENCES}

1. Kapur P, Caty MG, Glick PL. Pediatric hernias and hydroceles. Pediatr Clin North Am 1998;45:773-89. [CrossRef]

2. Manoharan S, Samarakkody U, Kulkarni M, Blakelock R, Brown S. Evidence-based change of practice in the manegement of unilateral inguinal hernia. J Pediatr Surg 2005;40:1163-6. [CrossRef]

3. George EK, Oudesluys-Murphy AM, Madern GC, Cleyndert $\mathrm{P}$, Blomjous JG. Inguinal hernias containing the uterus, fallopian tube, and ovary in premature female infants. $J$ Pediatr 2000;136:696-8. [CrossRef]

4. Shadbolt CL, Heinze SB, Dietrich RB. Imaging of groin masses: inguinal anatomy and pathologic conditions revisited. Radiographics 2001;21:261-71. [CrossRef]

5. Laing FC, Townsend BA, Rodriguez R. Ovary-containing hernia in a premature infant: Sonographic diagnosis. J Ultrasound Med 2007;26:985-7.

6. Okada T, Sasaki S, Honda S, Miyagi H, Minato M, Todo S. Irreducible indirect inguinal hernia containing uterus, ovaries, and Fallopian tubes. Hernia 2012;16:471-3. [CrossRef]

7. Goske MJ, Emmens RW, Rabinowitz R. Inguinal ovaries in children demonstrated by high resolution real-time ultrasound. Radiology 1984;151:635-6. [CrossRef]

8. Boley SJ, Cahn D, Lauer L, Weinberg G, Kleinhaus S. The irreducible ovary: a true emergency. J Pediatr Surg 1991;26:1035-8. [CrossRef]

9. Cascini V, Lisi G, Di Renzo D, Pappalepore N, Lelli Chiesa P. Irreducible indirect inguinal hernia containing uterus and bilateral adnexa in a premature female infant: report of an exceptional case and review of the literature. J Pediatr Surg 2013;48:17-9. [CrossRef]

10. Ming YC, Luo CC, Chao HC, Chu SM. Inguinal hernia containing uterus and uterine adnexa in female infants: report of two cases. Pediatr Neonatol 2011;52:103-5. [CrossRef] 